pp. $461-477$

\title{
The Influence of Encounter Service Quality on Patient Satisfaction: An Empirical Study in Chinese Public Hospitals
}

Submitted 23/03/20, $1^{\text {st }}$ revision 02/05/20, $2^{\text {nd }}$ revision 30/06/20, accepted 30/07/20

\author{
Wenxin, W. ${ }^{1}$, Bentum-Micah, G. ${ }^{2}$, Zhiqiang, M. ${ }^{3}$, Bing, L. ${ }^{4}$,
} Asabea Addo, A. ${ }^{5}$, Boadi, B.E. ${ }^{6}$, Atuahene, A.S. ${ }^{7}$, Bondzie-Micah, V. ${ }^{8}$ Abstract:

Purpose: This paper examined the association between perceived service quality and patient satisfaction of Chinese out-patients in the patronage of medical services.

Design/Methodology/Approach: Utilizing by novelty specific departments in the hospital's and logistics multiple regression investigation, the researchers tested and estimated the statistical effects of the department's services (perceived service quality) as a predictor for out-patients satisfaction.

Findings: The analysis shows that patients who exhibited content from the services of selected departments reported greater satisfaction, with it impacts suggesting a measurably noteworthy effect, even in a total medical seller market like China.

Practical Implication: The study brings forth implications both for professionals and academics. It encourages more studies, and its findings and application can provide value as a management tool to consider and identify sources as linking the relationship between potential improvements in perceived service quality from as low as departmental levels and patient's satisfaction to achieve advantage.

Originality/Value: It encourages more studies, and its findings and application can provide value as a management tool to consider and identify sources as linking the relationship between potential improvements in perceived service quality.

Keywords: Access to care, out-patients, patients' satisfaction/fulfillment, service quality.

JEL Classification: I10, I12, I18.

Paper Type: Research article.

Acknowledgments: The authors would like to appreciate the investigative group for their priceless bolster of this project. And the various hospitals included in the study for allowing their inclusion in the studies.

\footnotetext{
${ }^{I}$ Corresponding author, Department of Public Administration, Law School, Shantou University, P.R. Chinawxwang666@126.com;

${ }^{2}$ School of Management, Jiangsu University, P.R. China

${ }^{3}$ School of Management, Jiangsu University, P.R. China

${ }^{4}$ Corresponding author, School of Public Health and Administration, Hubei University of Medicine, P.R. China $1354846891 @$ @q.com;

${ }^{5}$ School of Management, Jiangsu University, P.R. China

${ }^{6}$ School of Management, Jiangsu University, P.R. China

${ }^{7}$ School of Management, Jiangsu University, P.R. China

${ }^{8}$ School of Public Affairs, University of Science and Technology of China, Anhui, P.R. China
} 


\section{Introduction}

Over the past two decades, literature on patient satisfaction have grown much attention for the reason that it gives healthcare providers and administrators the chance to improve the services in healthcare organizations (Al-Neyadi, Abdallah, and Malik, 2018; Poksinska, Fialkowska-Filipek, and Engström, 2017). Yielding to these effects are how consumers of the medical services are becoming more and more sophisticated about the type of service they receive (Meesala and Paul, 2018). This has hinted service providers to become more attentive to clientage concerns and intensifying competitions from other health providers, causing a pull of social scientists to becoming more involved in health services research with government support in such research on the increase (Mendes et al., 2018).

Patient satisfaction for the most part shows up to speak to attitudes towards care or perspectives of care (Batbaatar, Dorjdagva, Luvsannyam, Savino, and Amenta, 2017; Kruse et al., 2017). The exhibit of quality results and patient fulfillment with services rendered them (patients) are presently a need and the essential competitive edge in healthcare arrangement as healthcare benefactors request excellence in care services from care suppliers and measure such excellence against their expectations (Kasiri, Cheng, Sambasivan, Sidin, 2017; Ramli, 2019; Setyawan, Supriyanto, Tunjungsari, Hanifaty, and Lestari, 2019).

A falling apart healthcare delivery system has gotten a critical attention as a public well-being issue in the Chinese health care framework driven by a rise in a vicious wave of violence against medical practitioners (Lee et al., 2018; Zhou, Zhao, Campy, and Wang, 2017). Violence within this setting has often than not, believed to have originated from medical disputes (which include civil, administrative or even criminal liability) and the widely failed patient-physician relationship (Yang, Zhang, Shen, $\mathrm{Li}$, and $\mathrm{Wu}, 2013$ ). Whilst poor patient-provider effects have been considered to be an indicator for this rising severity and predominance of savagery against health care providers in China (Lee et al., 2018; Liu, Vortherms, and Hong, 2017b; Zhou et al., 2017), the challenge of this connection has been addressed as been closely related with providers' practices (He, 2014; Wang et al., 2018), as well as patients' lack of adherence to treatment. A publication within the Lancet expressed that "patient dissatisfaction in China," which may well be a close correlate of patient-provider relationship (Sun et al., 2017), "should be considered not just as the cause of brutishness against specialists or consultants, but as a side effect of an imperfect system that victimizes both patients and specialists alike" (Lancet, 2014).

China amidst its major healthcare restructurings, have focused on reforms that embraces improving access to primary care and patient-provider relationships (Liu, Vortherms, and Hong, 2017a). As part of this health care reform, China has tested hospital mechanisms that seek to address the vicious cycle of violence including laws tilted at medical practices, which stipulates that there shouldn't be any form of "extortion or illegal acceptance property or other illegitimate gains" in healthcare 
delivery (National People's Congress, 2005) 'Law of the People's Republic of China on Medical Practice' (Zhu, Wang, and Yang, 2018). However, because of the shift in the Chinese healthcare sector's revenue source from the central government to the market selling expensive drugs and the use of sophisticated medical equipment, has provided ways to earn extra revenue for Chinese healthcare institutions and doctors.

Such profit-driven activities of the Chinese healthcare sector has not only created a social gap that leaves little to no room for the satisfaction concerns of it healthcare patrons but has also deteriorated patients' trust in Chinese healthcare institutions and providers (Zhang and Sleeboom-Faulkner, 2011). While this shift could allow some patients build a more personal relationship with their healthcare providers in the hopes of receiving better care, it can also be same sabotaging the patient-provider relationship for the masses that birth such violence (Yang, 2016). To fill this gap, this research aimed at understanding and hence bridging the gap of dissatisfaction creation, that fosters this flawed system, and victimizes both service providers and patients alike, which could as well be one of the only antidotes to this vicious cycle of predominant client-provider violence in the Chinese public healthcare system (Lancet, 2014).

Across the globe, vigorous evidence indicates a strong constructive relationship amid patient satisfaction and patients perceived service quality (Al-Mhasnah, Salleh, Afthanorhan, and Ghazali, 2018; Al-Neyadi et al., 2018; Rosha and Kaur, 2018). Drawing on the work of Dagger, Sweeney, and Johnson, (2007), they argued that to fully understand perceived service quality creation in healthcare service delivery which closely drives satisfaction, every process and activity the patient engaged or experienced before and after the time of service delivery should be considered as a possible predictor of the quality of service and hence satisfaction creation. Literature in evidence shows that, even though service quality is a known close correlate of satisfaction in most cross-sectional data studies, causality amongst the two variables is not always very clear. Agreeing to a subjective study conducted in China, patient's satisfaction "is shaped" by patient's perceived service quality, as well as reasonableness and openness of care (Shan et al., 2016).

It would only be reasonable given the empirical findings in the past, to hypothesis a strong positive relationship of patients perceived service quality on patient's fulfillment and also holding all other factors constant, the level of patient satisfaction directly affecting positively the client-provider relations and reducing the victimization cycle and attitudes towards patronage of medical services. Therein, we assess the hypothesized model in which the influence of patients' perceived service quality via departmental services on patient fulfillment affects the patronage of medical services in public Chinese hospitals. The information gathered from this study will help healthcare managers to design excellent strategies that will improve service quality and management activities (Fatima, Malik, and Shabbir, 2018). 


\subsection{Theoretical Framework and Hypothesis}

\subsubsection{Healthcare Service Quality}

Service quality is recognized as a basic prerequisite for setting up and supporting fulfilling connections with esteemed clients (Salameh, Ahmad, Zulhumadi, and Abubakar, 2018). In spite of the fact that a significant amount of research has been published within the area of service quality perceptions, much of this research has centered on the advancement of generic service quality models drawing examples from Brady and Cronin Jr. (2001), Parasuraman, Zeithaml, and Berry (1988). Relatively, few studies, in comparison, have centered on the advancement of context-specific service quality models, in spite of signs that service quality assessments are likely to be setting dependent (Asinyo, 2015; Bezerra and Gomes, 2016). Essentially, research in evidence has not specifically examined how clients evaluate health service quality on specific contextual basis, even though it is widely accepted as judgment of a service often labelled in terms of the discrepancy between consumers' expectations and actual service performance (Chang, Chen, and Lan, 2013).

Following critics and failed attempts of the traditional SERVQUAL scale to replicate results of context-specific service quality as in the context of health care services with mixed results, (Brady and Cronin Jr., 2001) in their work, argued a rather perceptive approach to measuring service quality, suggesting service quality perceptions be comprised of four predominant dimensions of interpersonal quality, technical quality, environment quality, and administrative quality which are context objective. In this vain, service quality has further been suggested as possibly most appropriately conceptualized as a formative construct than a reflective one (Dabholkar, 2015; Dabholkar, Shepherd, and Thorpe, 2000), as it gives rise to the overall construct. Agreeing to this approach Dagger et al. (2007) argue that, "it does not make sense to suggest that high levels of technical service quality are the result of high overall service quality perceptions, as implied by the traditional reflective approach to modeling service quality and its dimensions, but rather that as technical service quality increases, overall service quality perceptions increase".

Drawing on the foundations of Brady and Cronin Jr. (2001), and Dagger et al. (2007) developed and validated a reliable health care service quality scale based on four dimensions, reflecting (50) items with (9) subdimensions (interaction, relationship, outcome, expertise, atmosphere, tangibles, timeliness, operation, support) to measure service quality perceptions from the customer's perspective. They argued that to fully understand perceived service quality creation in healthcare service delivery which closely drives satisfaction and loyalty intentions, context processes and activities the patient engaged or experienced during the service delivery should be considered as a possible predictor of the quality of service and hence satisfaction creation based on the proposed four (4) dimension and nine (9) subdimensions. Works in literature suggests two alternative perspectives regarding the relationship amid service quality and satisfaction. The first been transaction 
perspective and practice, (Bitner and Hubbert, 1994; Mohr and Bitner, 1995), which considered satisfaction an antecedent to a worldwide appraisal of perceived service quality on the premise that an accumulation of transaction-specific satisfaction judgments will result in a broader, global assessment of service quality and the second point of view sets that service quality, as a cognitive assessment, goes before the more emotive satisfaction construct (Brady and Cronin Jr., 2001; Cronin Jr. and Taylor, 1992). Based on the running lines of arguments we thus infer that:

Hypothesis 1: All the departmental service quality items will have a significant positive impact on the patient's perceived service quality, within the patronage of the medical services.

\subsubsection{Concept of Patient Satisfaction}

The issue of patient fulfillment with healthcare has picked up expanding consideration from administrators, professionals, consumers and assesses of wellbeing care. One reason for this consideration is that understanding satisfaction is seen to be one of the many objectives of healthcare conveyance. In any case, it is greatly difficult to definitely characterize patient fulfillment due to the indecisive prove in literature (Aduo-Adjei, 2015; Ahmed, Tarique, and Arif, 2017; Anabila, 2019). Satisfaction is essential to large success of healthcare suppliers, since it has the probability to reinforce hospital image, coming about in expanded service utilization, increased market share and long-term competitive gain (Boadi, Wenxin, Bentum-Micah, and Jerry, 2019; Ferrand et al., 2016), usually due to the reality that service quality enhancement has had a significant part to play in forming patients' judgements in a way that bears on their well-being seeking behaviors (Iqbal and Shah, 2016).

Patient satisfaction/fulfillment is the key figure that drives when the performance of the service surpasses desires. It is a post-purchase state of consumers' intellect that mirrors how much the customer likes or dislikes the service after encountering it (Jamaluddin and Ruswanti, 2017). Consumer's fulfillment may be a guide for observing and making strides the current and potential performance of healthcare administrations (Kasiri et al., 2017; Zairi, 2000), as it leads to customer's dependability, recommendations and repeat buy (Meesala and Paul, 2018).

\subsubsection{Service Quality and Consumer Satisfaction}

Adequate reference in study support the linkages amid service quality and consumer satisfaction as one key objective of any firm seeking long-term relationship and retention of new customers (Kasiri et al., 2017; Li et al., 2015; Meesala and Paul, 2018). In the healthcare context where contacts with clienteles are one of the core processes, satisfaction is critical for sustainability and profitability (Tenkorang, 2016; Xing et al., 2015). One of the main essentials defining customer satisfaction is the customer's perception of the service quality (Asnawi, Awang, Afthanorhan, Mohamad, and Karim, 2019). Client satisfaction is described as the result of a comparison of customers' expectations and his or her subsequent perceived 
performance of a service (Jiang and Zhang, 2016). On the basis of this prior research, we also adopted the position that overall service quality perceptions would be likely to impact the health service satisfaction of patients. This follows the early work of Dagger et al. (2007), Duan, Qiu, Yu, and Hu, (2014), who proposed that overall service quality and satisfaction result from the evaluation of certain components, such as admissions, nursing, and housekeeping, in a health care context. Based on the afore mentioned relations in literature, we hypothesize that:

Hypothesis 2: Overall health service quality has a significant positive impact on health service satisfaction among patients within the patronage of medical administrations.

\section{Materials and Methods}

\subsection{Information Source and Study Populace}

The information for this investigation was collected from a cross-sectional study directed with a large test populace of out-patients in eleven (11) large hospitals in Hubei province central China. The hospitals were selected through a three-stage sampling, first from the provincial level, hospitals level and then the respondent level. The province, central China's Hubei was purposefully sampled as it proved useful to the research design. Second, leading hospitals spear heading participation in recent reforms in the province was selected and lastly respondents (patients) were recruited from each hospital. The data was collected approximately within a month between July and August using census sampling technique which involved identifying all possible out-patients to the hospitals, and a self-administered questionnaire was filled. Within waiting areas in the hospitals, out-patients who were approached, had willingness and consent, were literate in Mandarin Chinese, were both physically and mentally sound during the data collection period were included in the study survey. 7,108 survey questionnaires were anonymously completed by patients within the span of the data collection from the selected hospitals. $20-30 \%$ accounted for range of non-response rate.

\subsection{Study Factors}

Basic demographic data with respect to the patient's gender, place of residence (i.e., within the city, outside the city, outside the province, foreign or Hong Kong, Macao, Taiwan), their hospital registration type (i.e., normal number, expert number, professor number, special number or convenient clinic) were collected. Other control variables as birth year, expenses type and even mode of registration were all collected but not reported as it did not prove useful for the hypothesis and analysis.

The overall satisfaction with the experience of visiting the hospital and benefiting from the services of the hospital, was used as a dependent variable-proxy for patient's satisfaction. It was controlled utilizing a single-item measure consisting of 
6 Likert-type answer groupings: very satisfied, satisfied, general, dissatisfied, very unsatisfied and skipped. The predictor variables (perceived service quality items) utilized within the study comprises of 9 variables with 6 Likert-type response consortiums: very satisfied, satisfied, general, dissatisfied, very unsatisfied and skipped. After coding and reverse-coding negative items, the 9 items were used as predictor variables to test the relationship between the out-patients satisfaction and perceived service quality of the respondents. The internal reliability of the constructs measured utilizing Cronbach's alpha among the 10 variables of the study populace was 0.84 .

The model in all controlled for 9 items predicting out-patient satisfaction, service accuracy of the referral staff, order and treatment in waiting area, doctor services rendered the patient, pharmacy services, auxiliary services, hygienic conditions in the public area of the hospital, accuracy and clear information of route/guide signs in and around the hospital, hospitals effectiveness in handling complaints and the medical cost of services rendered the out-patients.

\subsection{Statistical Analyses}

The patients' characteristics were defined using mean, frequency and standard deviation and percentage scores. A bivariate analysis was performed to examine the relationship between each of the participating constructs, while a regression analysis was done to look at the hypothesized relationship between patient's fulfillment and the perceived service quality items. A statistically significant impact of the predicting factors on the dependent variable suggested a favorable patients' general attitude towards the hospital's services. A traditional logistics regression analysis was performed based on the assumed model and hypothesis. No multicollinearity was observed amongst the predicting variables. All statistical analysis was performed with SPSS v24.

Figure 1. Assumed model and hypothesis showing the structural relationship between perceived service quality and patient fulfillment

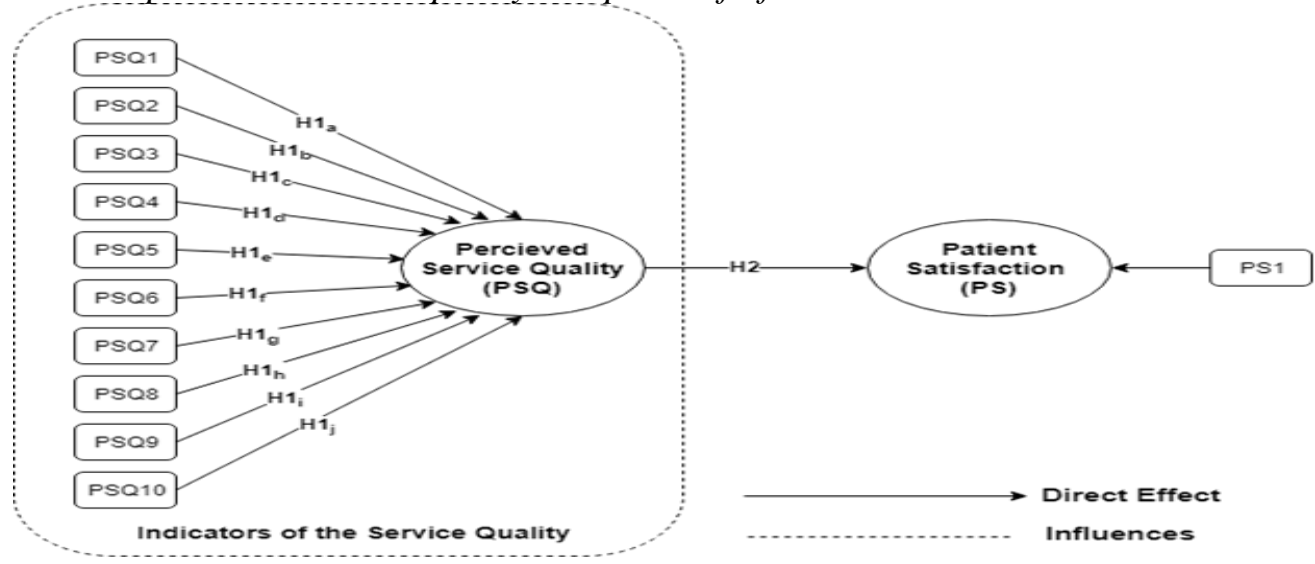




\section{Results}

\subsection{Demographic Characteristics}

This research included 7,108 patients from 11 Chinese public hospitals in the central Hubei province of China. As shown in Table 1 participating patients were males $(41.5 \%)$ and females $(58.5 \%)$ and majority been residents living within the city $(80.9 \%)$ where the hospitals are located. About $(63 \%)$ of the patients reported to have registered for treatment services through the normal number reservation type and expert and others spanning across $(36.1 \%)$ and $(0.4 \%)$ respectively.

Table 1. Patients' sociodemographic characteristics

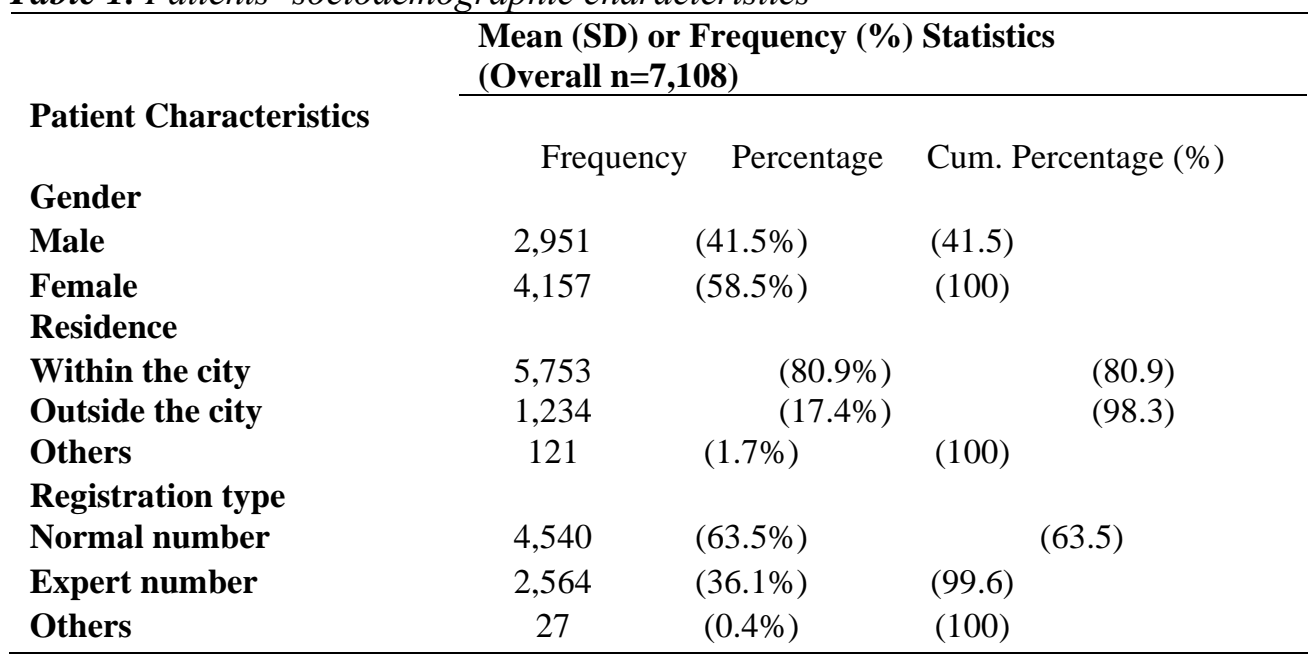

Note: Abbreviations: $S D .=$ Standard Deviation, $(N)=$ Population Size, $M=$ Mean

Source: Authors contribution using SPSS.

Table 2. Analysis of variance (ANOVA) and Model Summary

\begin{tabular}{llllllll}
\hline Model & $\begin{array}{l}\text { Sum of } \\
\text { squares }\end{array}$ & $\begin{array}{l}\text { Mean } \\
\text { square }\end{array}$ & F & Sig. & $\begin{array}{l}\text { R } \\
\text { Squar } \\
\text { e }\end{array}$ & $\begin{array}{l}\text { Adjuste } \\
\text { d } \\
\text { R } \\
\text { Square }\end{array}$ & $\begin{array}{l}\text { Durbin } \\
\text { Watso } \\
\text { n }\end{array}$ \\
\hline Regressio & 904.271 & 90.427 & 496.687 & $.000^{* *}$ & .624 & .623 & 1.113 \\
$\mathbf{n}$ & 544.544 & 0.182 & & & & & \\
$\begin{array}{l}\text { Residual } \\
\text { Total }\end{array}$ & 1448.814 & & & & & & \\
\hline
\end{tabular}

Note: Abbreviations: $F .=F$ static value, Sig. $=$ Significance $* *<0.01$

Source: Authors contribution using SPSS.

\subsection{Model Summary}

From Table 2, the R-square showed a significant value of .624 above the minimum accepted threshold of 0.30 , which means a good explaining power of this model. The 
adjusted R-square is at .623 suggested the degree of change within the dependent variable as a result of changes within the autonomous or indicator factors. DurbinWatson test applied to this model also showed a positive autocorrelation of 1.113 , suggesting positive relationship amid the predictor variables and the dependent variable adopted for the study. The analysis of variance (ANOVA) for the hypothesized model adopted for this study specifies the model into the various sum of squares, degree of freedom for the variables, the F-value and its level of significance. The model shows a statistically significant model fit at an F-static of $(\mathrm{F}=496.687)$ at a significance value of $(\mathrm{P}<0.000)$.

Table 3. Regression coefficients of the dependent variable (Patient Satisfaction)

\begin{tabular}{|c|c|c|c|c|c|c|c|c|c|}
\hline \multirow[b]{2}{*}{ Model } & \multicolumn{2}{|c|}{$\begin{array}{l}\text { Standardized } \\
\text { coefficients }\end{array}$} & \multirow[t]{2}{*}{$t$} & \multirow[t]{2}{*}{ Sig. } & \multirow{2}{*}{$\frac{\text { Correlation }}{\text { Zero order }}$} & \multicolumn{3}{|c|}{ Collinearity statistics } & \multirow[b]{2}{*}{ VIF } \\
\hline & $\beta$ & Beta & & & & Partial & Part & $\begin{array}{l}\text { Tolera } \\
\text { nce }\end{array}$ & \\
\hline (Intercept) & .329 & & 5.602 & .000 & & & & & \\
\hline referral & .038 & .035 & 2.221 & .026 & .571 & .041 & .025 & .496 & 2.016 \\
\hline waiting & .094 & .095 & 4.873 & .000 & .673 & .089 & .055 & .327 & 3.052 \\
\hline D-services & .298 & .284 & 12.896 & .000 & .732 & .229 & .145 & .259 & 3.859 \\
\hline A-services & .094 & .088 & 4.029 & .000 & .683 & .073 & .045 & .265 & 3.772 \\
\hline P-services & .071 & .068 & 3.213 & .001 & 669 & .059 & .036 & .282 & 3.540 \\
\hline circumstance & .087 & .081 & 4.392 & .000 & .628 & .080 & .049 & .372 & 2.688 \\
\hline Information & .095 & .085 & 3.829 & .000 & .683 & .070 & .043 & .253 & 3.959 \\
\hline Complaint & .153 & .171 & 8.622 & .000 & .683 & .156 & .097 & .320 & 3.121 \\
\hline Residence & -.049 & -.027 & -2.421 & .016 & -.023 & -.044 & -.027 & .997 & 1.003 \\
\hline
\end{tabular}

Note: a. Dependent variable: Patient satisfaction with the service received. Abbreviations: $t=t$-static value, Sig. =level of significance, VIF=Variance Inflation Factor, $\beta=$ Coefficient .

Source: Authors contribution using SPSS software.

No collinearity issue was identified based on the variance inflation factors (VIF) as the values reported are clearly below the threshold of 5 in principle. The study results presented in Table 3 above from the estimated statistics for the dependent variable coefficients shows:

Order and treatment in waiting area $(\beta=.094, t=4.873, P=.000 *,<0.05)$,

Doctor treatment services $\left(\beta=.298, t=12.896, P=.000^{*},<0.05\right)$,

Pharmacy department services $\left(\beta=.071, t=3.213, P=.001^{*},<0.05\right)$,

Auxiliary department services $\left(\beta=.094, t=4.029, P=.000^{*},<0.05\right)$,

Hygienic conditions in the public area of the hospital $\left(\beta=.087, t=4.392, P=.000^{*}\right.$, $<0.05$ ),

Accuracy and clear information of routelguide signs in and around the hospital area $(\beta=.095, t=3.829, P=.000 *,<0.05)$,

Hospitals effectiveness in handling complaints of out-patients $(\beta=.153, t=8.622$, $\left.P=.000^{*},<0.05\right)$.

Medical cost of services rendered the out-patients per their medical condition and treatment, were all seen to have a positive influence on the satisfaction of the outpatients with positive coefficients highlighting the positive impacts of the predictor 
variables on the dependent variable, the patient's satisfaction. With an absolute tstatic value of 12.896 at a significance of less than $\left(\mathrm{p}<0.01^{*}\right)$ error margin of the normal threshold of $(\mathrm{p}<0.05)$, the Doctor services in this study indicated highly statistically significant effect. The ability of the hospitals to handle complaints of the patients effectively also showed very statistically significant effects with an absolute $\mathrm{t}$-value of $(\mathrm{t}=8.622)$ at less than $(\mathrm{p}<0.01 *)$ significance level. The orderliness while awaiting treatment in the hospitals respective waiting areas with the auxiliary form of services received by the respondents were also very statistically significant at an absolute $\mathrm{t}$-value of $\left(\mathrm{t}=4.87 ; \mathrm{p}<0.01^{*}\right)$ and $(\mathrm{t}=4.02: \mathrm{p}<0.01)$ correspondingly. The pharmacy department services also reported statistically significant effects on the patient's satisfaction at an absolute $\mathrm{t}$-value ( $\mathrm{t}=3.213)$ and at an error margin of less than $(p<0.01 *)$ of the $(p<0.05)$ threshold. The variable residency is shown with an inverse coefficient of $(\beta=-.049)$ at an absolute $t$-static of $(t=2.33)$ with significance of $(\mathrm{P}=0.016,<0.05)$ error margin. The service accuracy of the referral staff and department $(\beta=.038, \mathrm{t}=2.221, \mathrm{P}=.026,<0.05)$ this study suggested were statically significant, registering the pleasure of the patients with regards to the services provided them in this department.

Figure 2. The final framework with significant T-statistics and P-values of the Structural association between perceived service quality and patient satisfaction

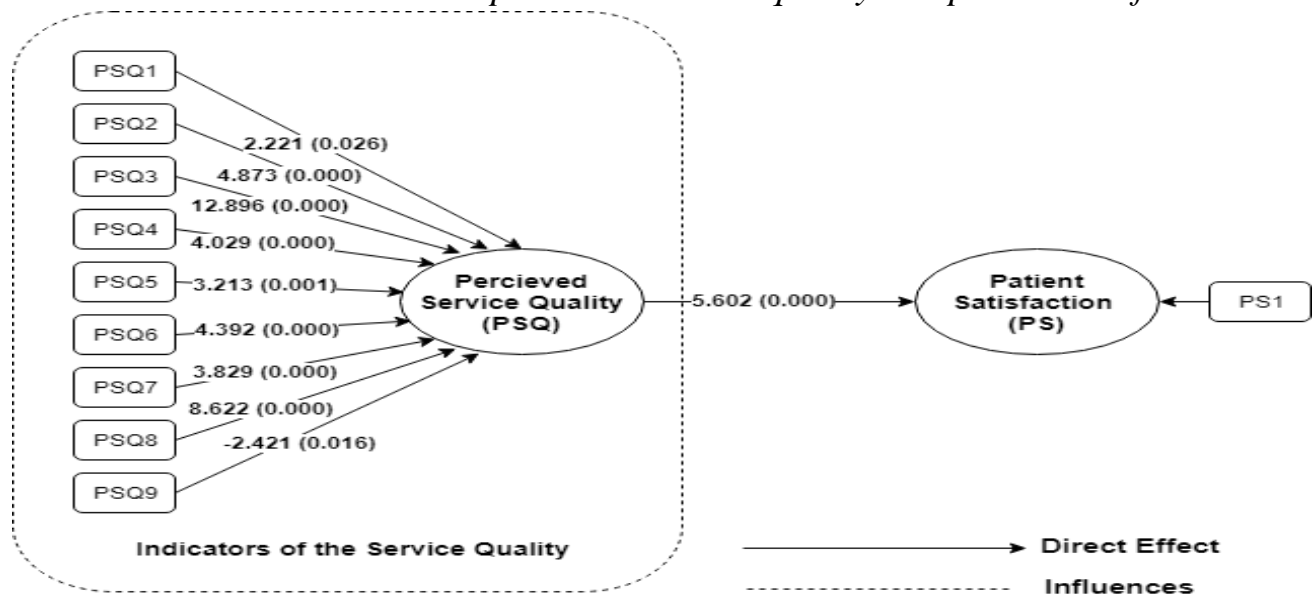

For the ease of graphical viewing, Figure 2 is presented. It draws on the logistics regression analysis adopted in Table 3 to bring a more simplified graphical view of the analysis. To test for the structural association between perceived service quality variables and patient satisfaction as adopted in this study, the researchers first tested the predictability of the factor loadings of the perceived service quality variables as true measure of the quality of service. With that examined and established, the researchers tested the direct relationship of these quality item variables as a sum predictor of the satisfaction of a patient, having received services from the hospital. This was all done by utilizing the regression function in SPSS v.23. 
Grounded on the results of the research and for comfort of graphic checking of the hypotheses and their concluding status, we set out Table 4 below the test results as follows:

Table 4. Structural Relationship of the Test Result

\begin{tabular}{|c|c|c|c|}
\hline Hypothesis & Hypotheses Statement & Sig. Value & Conclusions \\
\hline $\mathbf{H 1}_{\mathbf{a}}$ & $\begin{array}{l}\text { The influences of the services of } \\
\text { the referral department has a direct } \\
\text { impact on perceived service } \\
\text { quality of the hospital }\end{array}$ & $0.026 *$ & Data supports the hypothesis \\
\hline H1 & $\begin{array}{l}\text { The influences of the services of } \\
\text { the waiting area department has a } \\
\text { direct impact on perceived service } \\
\text { quality of the hospital }\end{array}$ & $0.000 * *$ & Data supports the hypothesis \\
\hline H1 & $\begin{array}{l}\text { The hospital's Doctor/Physician } \\
\text { services has a direct impact on } \\
\text { perceived service quality }\end{array}$ & $0.000 * *$ & Data supports the hypothesis \\
\hline $\mathbf{H 1}_{\mathrm{d}}$ & $\begin{array}{l}\text { The influences of the services of } \\
\text { the auxiliary departments has a } \\
\text { direct impact on perceived service } \\
\text { quality of the hospital }\end{array}$ & $0.000 *$ & Data supports the hypothesis \\
\hline H1e & $\begin{array}{l}\text { The influences of the services of } \\
\text { the Pharmacy department has a } \\
\text { direct impact on perceived service } \\
\text { quality of the hospital }\end{array}$ & $0.001 * *$ & Data supports the hypothesis \\
\hline H1f & $\begin{array}{l}\text { The influences of the state of } \\
\text { hygiene in has a direct impact on } \\
\text { perceived service quality of the } \\
\text { hospital }\end{array}$ & $0.000 *$ & Data supports the hypothesis \\
\hline H1 g & $\begin{array}{l}\text { The Accuracy and clear } \\
\text { information of route/guide signs } \\
\text { has a direct impact on perceived } \\
\text { service quality of the hospital }\end{array}$ & $0.000 * *$ & Data supports the hypothesis \\
\hline $\mathbf{H 1}_{\mathrm{h}}$ & $\begin{array}{l}\text { The Hospitals effectiveness in } \\
\text { handling complaints has a direct } \\
\text { impact on perceived service } \\
\text { quality of the hospital }\end{array}$ & $0.000 * *$ & Data supports the hypothesis \\
\hline $\mathbf{H} \mathbf{1}_{\mathbf{i}}$ & $\begin{array}{l}\text { The medical cost of services and } \\
\text { residency of patients has a direct } \\
\text { impact on perceived service } \\
\text { quality of the hospital }\end{array}$ & $0.016^{*}$ & Data supports the hypothesis \\
\hline H2 & $\begin{array}{l}\text { Perceived Service Quality exerts a } \\
\text { direct significant and positive } \\
\text { effect on Chinese patients' } \\
\text { fulfillment in the selected hospitals }\end{array}$ & $0.000 * *$ & Data supports the hypothesis \\
\hline
\end{tabular}

Source: Authors' contribution using SPSS, (**p<0.01, *p<0.05)

\section{Discussion}

Utilizing cross-sectional information from 11 Chinese public hospitals in the central Hubei province of China, the study bid to assess the connection amongst perceived service quality and patient satisfaction/fulfillment of out-patients in the selected 
hospitals and how this relationship affects the patronage of the hospital's services. The studies exhibited that patients who displayed contentment from the predictor variables adopted in this study showed greater satisfaction indicating not just a positive relationship but also a good fit for this model and its hypothesis. The logistic multiple regression analysis used indicated that, there's a positive relation amid the perceived service quality items and patient satisfaction, which underlines our conceptual understanding of positive patients' general attitudes towards services rendered them by the hospitals.

Satisfaction is an individual perception and therefore difficult to define or measure (Nasution, Sembada, Miliani, Resti, and Prawono, 2014). However, Patient satisfaction with medical care is maybe one of the foremost commonly measured patients' attitudes, and work in this field has expanded remarkably with the intent of reducing patient displeasure or dissatisfaction to the barest minimum and hence increase positive attitudes towards hospital services and patronage (Bramley and Matiti, 2014). Hassan, Nawaz, Lashari, and Zafar (2015) posits that quality of service and satisfaction are critical indicators that cement the connection between organizations and its customers. This is because, unlike service quality, perceived service quality is exceptionally subjective and can be assessed as high or low based on each patients judgement (Mosadeghrad, 2014).

As hypothesized, the studies found that patients who benefitted and showed content with the perceived service quality items adopted in this study showed greater satisfaction, and this is in line with already detailed relationship amid patient satisfaction/fulfillment and perceived quality of healthcare administrations. As a case the study by Hawthorne, Sansoni, Hayes, Marosszeky, and Sansoni (2014) examined the impacts measuring patient fulfillment with well-being care treatment utilizing the short evaluation of patient fulfillment which conveyed predominant and strong fulfillment gauges. Other studies by Price et al. (2014) and Lee, Chen, Chen, and Chen, (2010) decreased the close relationship amid patients' perceived service quality and patient satisfaction/fulfillment.

Even though many studies have looked at the impact of service quality on patient satisfaction within the health care service conveyance, yet, assessment of their relationship coupled with their effects in specific areas in the healthcare system in a total seller market as adopted in this study are still understudied.

Connecting the relationship between potential enhancements in perceived service quality items as adopted in this study of healthcare services and patients satisfaction, this study adds to the existing work showing that perceived service quality items as used in this study serves as an opportunity to make strides in patients satisfaction and subsequently construct more positive patient attitudes in the patronage of healthcare services. 


\subsection{Theoretical and Managerial Implications}

This study does come with implications both for academia and practical purposes in the light that, in a total medical seller market as in the case of the Chinese, the area of satisfaction of the patient seen through the quality of service is under-researched both to the practicing managers and scholars alike. In academia and practice, this study suggests that, connecting the relationship amid quality of service and the satisfaction of the patient not only inspires the practitioners towards goals orientation, but also limits the negative attitudes and behaviors emanating from a flawed system that victimizes both parties (provider-client) to the service to ensure the expected outcomes.

Also, this paper reveals a new arena of research to the academics and professionals alike, for identifying potential satisfier from as low as departmental levels services to neutralize the non-productive or counter-productive behaviors of parties (providerclient) that birth violence in the bid to limiting it, as the relative impact of these purported violence behavior in service organizations as the case of this study, is severely harmful not only to the client but also to the practitioners as they are the direct producers of the service.

The study implies that, these checks and balance amidst a flawed system that has little to no consideration for the satisfaction of its patrons; hence victimizing both parties to the service, will help subsidize the negative effects and non-productive behaviour of parties in the cause of service delivery and hence improve performance. Following the understanding and suggestions as proposed by Dagger et al. (2007), in their work on health service quality, scale development, this study in conjunction with past studies on an attempt to lessening patient displeasure or dissatisfaction that births violence across access to public healthcare delivery in China, suggests linking the connection between improving service quality from as low as the departmental levels and out-patients satisfaction has a potential to augment patients' attitudes in lessening violence towards and during the patronage of out-patient medical services in China.

\section{Conclusion}

The study has answered the questions, is there an association among service quality and satisfaction creation among Chinese out-patients? and how this relationship affects the patient's attitude towards the patronage of the services of the hospital, bridging the flawed system that victimizes both patients and practitioners alike. Whereas this study gives a favorable prove for improving service quality and hence it impacts on out-patient satisfaction, this study is limited from the cross-sectional design and a more longitudinal studies is required to conclude causal relationship between the influences and extra studies suggested for assessing its long-term effect. Even though the sample size is more than enough to draw conclusions and make inferences, choice of inclusion of more hospitals is suggested for a more balanced 
generalization of the findings across a wider spectrum of the healthcare service industry in China.

\subsection{Research Limitations and Future Study Agenda}

The study does have some limitations. Data used for the study relied solely on selfreported data from the respondents, and the reported data could not be verified (e.g., benefitted from the service quality items included in the study). The study did not permit for examination of the long-term impacts of the service quality items on outpatient satisfaction in this study. Thus, long-term follow-up studies is suggested for future research and assessment of the item's effect. This is because, on the case of residence, the results suggest, the longer a patient has lived in the city where the healthcare service is provided, the lesser they felt satisfied. In spite of the limitations, this study includes esteem, because it is one of the very few studies that has investigated the appraisal of the relationship of service quality and patient fulfillment coupled with their effects on the patronage of medical services in specific areas in the healthcare framework in China.

Ethical Considerations: Ethical issues (Including copyright infringement, informed consent, misconduct, information fabrication and/or distortion, double publication and/or submission, redundancy, etc.) have been duly observed by the authors.

Conflict of Interest: The authors pronounce that they have no conflict of interest with respect to this study.

Funding: The National Natural Science Foundation Project "The Mechanism and Policy Choice of Professional Spirit Molding for Doctors in Public Hospitals Driven by Dual Contracts" (Project Approval No. 71673121) and The National Natural Science Foundation Project "The study of inherent path and government support strategies to enhance the quality of public hospital services based on reconstruction of doctor-patient Integrity "(Project Approval No. 71373102).

\section{References:}

Aduo-Adjei, K. 2015. Patients Satisfaction with Quality Healthcare in Ghana: A Comparative Study between University of Ghana and University of Cape Coast Hospitals. University of Ghana.

Ahmed, S., Tarique, K.M., Arif, I. 2017. Service quality, patient satisfaction and loyalty in the Bangladesh healthcare sector. International journal of health care quality assurance, 30(5), 477-488.

AL-Mhasnah, A., Salleh, F., Afthanorhan, A., Ghazali, P. 2018. The relationship between services quality and customer satisfaction among Jordanian healthcare sector, Management Science Letters, 8(12), 1413-1420.

Al-Neyadi, H.S., Abdallah, S., Malik, M.J. 2018. Measuring patient's satisfaction of healthcare services in the UAE hospitals: Using SERVQUAL. International Journal of Healthcare Management, 11(2), 96-105. 
Anabila, P. 2019. Service quality: A subliminal pathway to service differentiation and competitive advantage in private healthcare marketing in Ghana. Health marketing quarterly, 36(2), 136-151.

Anhang Price, R., Elliott, M.N., Zaslavsky, A.M., Hays, R.D., Lehrman, W.G., Rybowski, L., . . Cleary, P.D. 2014. Examining the role of patient experience surveys in measuring health care quality. Medical Care Research and Review, 71(5), 522-554.

Asinyo, I. 2015. Measuring Higher Education Service Quality (A Study across Some Selected Universities in Ghana). University of Ghana.

Asnawi, A., Awang, Z., Afthanorhan, A., Mohamad, M., Karim, F. 2019. The influence of hospital image and service quality on patients' satisfaction and loyalty. Management Science Letters, 9(6), 911-920.

Batbaatar, E., Dorjdagva, J., Luvsannyam, A., Savino, M.M., Amenta, P. 2017. Determinants of patient satisfaction: a systematic review. Perspectives in public health, 137(2).

Bezerra, G.C.L., Gomes, C.F. 2016. Measuring airport service quality: A multidimensional approach. Journal of Air Transport Management, 53, 85-93.

Bitner, M.J., Hubbert, A.R. 1994. Encounter satisfaction versus overall satisfaction versus quality. Service quality: New directions in theory practice, 34(2), 72-94.

Boadi, E.B., Wenxin, W., Bentum-Micah, G., Jerry, I.K. 2019. Impact of Service Quality on Customer Satisfaction in Ghana hospitals: A PLS-SEM Approach. Canadian Journal of Applied Science Technology, 7(3), 503-511.

Brady, M.K., Cronin Jr.J.J. 2001. Some new thoughts on conceptualizing perceived service quality: a hierarchical approach. Journal of Marketing, 65(3), 34-49.

Bramley, L., Matiti, M. 2014. How does it really feel to be in my shoes? Patients' experiences of compassion within nursing care and their perceptions of developing compassionate nurses. Journal of clinical nursing, 23(19-20), 2790-2799.

Chang, C.S., Chen, S.Y., Lan, Y.T. 2013. Service quality, trust, and patient satisfaction in interpersonal-based medical service encounters. BMC health services research, $13(1), 22$.

Cronin, Jr. J.J., Taylor, S.A. 1992. Measuring service quality: a reexamination and extension. Journal of Marketing, 56(3), 55-68.

Dabholkar, P.A. 2015. How to improve perceived service quality by increasing customer participation. Paper presented at the Proceedings of the 1990 academy of marketing science (AMS) annual conference.

Dabholkar, P.A., Shepherd, C.D., Thorpe, D.I. 2000. A comprehensive framework for service quality: an investigation of critical conceptual and measurement issues through a longitudinal study. Journal of Retailing, 76(2), 139-173.

Dagger, T.S., Sweeney, J.C., Johnson, L.W. 2007. A hierarchical model of health service quality: scale development and investigation of an integrated model. Journal of service research, 10(2), 123-142.

Duan, G., Qiu, L., Yu, W., Hu, H. 2014. Outpatient service quality and doctor-patient relationship: a study in Chinese public hospital. International Journal of Services, Economics and Management, 6(1), 97-111.

Fatima, T., Malik, S.A., Shabbir, A. 2018. Hospital healthcare service quality, patient satisfaction and loyalty: An investigation in context of private healthcare systems. International Journal of Quality Reliability Management, 35(6), 1195-1214.

Ferrand, Y.B., Siemens, J., Weathers, D., Fredendall, L.D., Choi, Y., Pirrallo, R.G., Bitner, M. 2016. Patient satisfaction with healthcare services a critical review. Quality Management Journal, 23(4), 6-22. 
Hassan, R.S., Nawaz, A., Lashari, M.N., Zafar, F. 2015. Effect of customer relationship management on customer satisfaction. Procedia Economics and Finance, 23, 563.

Hawthorne, G., Sansoni, J., Hayes, L., Marosszeky, N., Sansoni, E. 2014. Measuring patient satisfaction with health care treatment using the Short Assessment of Patient Satisfaction measure delivered superior and robust satisfaction estimates. Journal of clinical epidemiology, 67(5), 527-537.

He, A.J. 2014. The doctor-patient relationship, defensive medicine and overprescription in Chinese public hospitals: evidence from a cross-sectional survey in Shenzhen city. Social Science Medicine, 123, 64-71.

Iqbal, M., Shah, A.B.A. 2016. The impact of customer satisfaction on customer loyalty: Mediating role of customer trust. Journal of Business Management Economic Studies, 1(1), 1-15.

Jamaluddin, J., Ruswanti, E. 2017. Impact of service quality and customer satisfaction on customer loyalty: a case study in a private hospital in Indonesia. Journal of Business Management decision, 19(5), 23-33.

Jiang, H., Zhang, Y. 2016. An investigation of service quality, customer satisfaction and loyalty in China's airline market. Journal of air transport management, 57, 80-88.

Kasiri, L.A., Cheng, K.T.G., Sambasivan, M., Sidin, S.M. 2017. Integration of standardization and customization: Impact on service quality, customer satisfaction, and loyalty. Journal of Retailing Consumer Services, 35, 91-97.

Kruse, C.S., Krowski, N., Rodriguez, B., Tran, L., Vela, J., Brooks, M. 2017. Telehealth and patient satisfaction: a systematic review and narrative analysis. BMJ Open, 7(8).

Lancet, T. 2014. Violence against doctors: why China? Why now? What next. The Lancet, 383(9922), 1013.

Lee, S., Wang, W., Washburn, D.J., Shi, H., Yu, Y., Du, Y., . . Maddock, J.E. 2018. Effect of the treatment-before-deposit policy on trust in physicians and perceived service quality among patients in 12 hospitals in China. The International journal of health planning management, 33(4), 1110-1120.

Lee, W.I., Chen, C.W., Chen, T.H., Chen, C.Y. 2010. The relationship between consumer orientation, service value, medical care service quality and patient satisfaction: The case of a medical center in Southern Taiwan. African Journal of Business Management, 4(4), 448-458.

Li, M., Lowrie, D.B., Huang, C.Y., Lu, X.C., Zhu, Y.C., Wu, X.H., . . Chen, S.Y. 2015. Evaluating patients' perception of service quality at hospitals in nine Chinese cities by use of the ServQual scale. Asian Pacific Journal of Tropical Biomedicine, 5(6), 497-504.

Liu, G.G., Vortherms, S.A., Hong, X. 2017a. China's health reform update. Annual Review of Public Health, 38, 431-448.

Meesala, A., Paul, J. 2018. Service quality, consumer satisfaction and loyalty in hospitals: Thinking for the future. Journal of Retailing Consumer Services, 40, 261-269.

Mendes, I.A.C., Trevizan, M.A., de Godoy, S., Nogueira, P.C., Ventura, C.A.A., Furlan, C.E.B. 2018. Expectations and perceptions of clients concerning the quality of care provided at a Brazilian hospital facility. Applied Nursing Research, 39, 211-216.

Mohr, L.A., Bitner, M.J. 1995. The role of employee effort in satisfaction with service transactions. Journal of Business Research, 32(3), 239-252.

Mosadeghrad, A.M. 2014. Factors influencing healthcare service quality. International journal of health policy management, 3(2), 77. 
Nasution, R.A., Sembada, A.Y., Miliani, L., Resti, N.D., Prawono, D.A. 2014. The customer experience framework as baseline for strategy and implementation in services marketing. Procedia-Social and Behavioral Sciences, 148, 254-261.

Parasuraman, A., Zeithaml, V.A., Berry, L.L. 1988. Servqual: A multiple-item scale for measuring consumer perc. Journal of retailing, 64(1), 12.

Poksinska, B.B., Fialkowska-Filipek, M., Engström, J. 2017. Does Lean healthcare improve patient satisfaction? A mixed-method investigation into primary care. BMJ Qual Saf, 26(2), 95-103.

Price, R.A., Elliott, M.N., Zaslavsky, A.M., Hays, R.D., Lehrman, W.G., Rybowski, L., . . Cleary, P.D. 2014. Examining the role of patient experience surveys in measuring health care quality. Medical Care Research and Review, 71(5), 522-554.

Ramli, A.H. 2019. Patient Satisfaction, Hospital Image and Patient Loyalty in West Sulawesi Province. Business Entrepreneurial Review, 17(1), 1-14.

Rosha, R., Kaur, D.N. 2018. Relationship between RATER Service Quality Dimensions and Customer Satisfaction-Study on Travel Agents in Punjab. Researchers World, 9(1).

Salameh, A.A.M., Ahmad, H., Zulhumadi, F., Abubakar, F.M. 2018. Relationships between system quality, service quality, and customer satisfaction. Journal of Systems Information Technology.

Setyawan, F.E.B., Supriyanto, S., Tunjungsari, F., Hanifaty, W.O.N., Lestari, R. 2019. The influence of medical staff services quality on patients satisfaction based on SERVQUAL dimensions. International Journal of Public Health, 8(1), 52-58.

Shan, L., Li, Y., Ding, D., Wu, Q., Liu, C., Jiao, M., .. . Hao, J. 2016. Patient satisfaction with hospital inpatient care: effects of trust, medical insurance and perceived quality of care. PLoS one, 11(10).

Sun, J., Hu, G., Ma, J., Chen, Y., Wu, L., Liu, Q., . . Liu, Y. 2017. Consumer satisfaction with tertiary healthcare in China: findings from the 2015 China National Patient Survey. International Journal for Quality in Health Care, 29(2), 213-221.

Tenkorang, E.Y. 2016. Health provider characteristics and choice of health care facility among Ghanaian health seekers. Health Systems Reform, 2(2), 160-170.

Wang, W., Zhang, H., Washburn, D.J., Shi, H., Chen, Y., Lee, S., . . Maddock, J.E. 2018. Factors influencing trust towards physicians among patients from 12 hospitals in China. American journal of health behavior, 42(6), 19-30.

Xing, K., Jiao, M., Ma, H., Qiao, H., Hao, Y., Li, Y., . . Liang, L. 2015. Physical violence against general practitioners and nurses in Chinese township hospitals: a crosssectional survey. PLoS One, 10(11), e0142954.

Yang, J. 2016. Informal payments and regulations in China's healthcare system: Red packets and institutional reform: Springer.

Yang, T., Zhang, H., Shen, F., Li, J.W., Wu, M.C. 2013. Appeal from Chinese doctors to end violence. The Lancet, 382(9906), 1703-1704.

Zairi, M. 2000. Managing customer satisfaction: a best practice perspective. The TQM Magazine, 12(6), 389-394.

Zhang, X., Sleeboom-Faulkner, M. 2011. Tensions between medical professionals and patients in mainland China. Cambridge Quarterly of Healthcare Ethics, 20(3), 458.

Zhou, M., Zhao, L., Campy, K.S., Wang, S. 2017. Changing of China' s health policy and Doctor-Patient relationship: 1949-2016. Health Policy, 6(3), 358-367.

Zhu, W., Wang, L., Yang, C. 2018. Corruption or professional dignity: an ethical examination of the phenomenon of "red envelopes"(monetary gifts) in medical practice in China. Developing world bioethics, 18(1), 37-44. 